\title{
Conhecimento e entendimento de enfermeiros sobre as ações gerenciais na atenção primária à saúde
}

\author{
Knowledge and understanding of nurses on the management actions on primary health care
}

\author{
Rosângela Nunes Almeida da Silvaa, Anna Kelly Martins Limab, Francidalma Soares Sousa Carvalho Filhac , \\ Jaiane de Melo Vilanovad, Francisco Laurindo da Silva ${ }^{\mathrm{e}}$

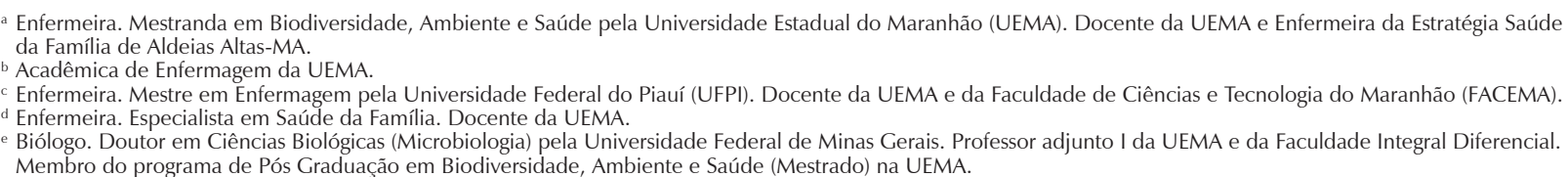 \\ Membro do programa de Pós Graduação em Biodiversidade, Ambiente e Saúde (Mestrado) na UEMA.
}

RESUMO Objetivo: Avaliar as ações gerenciais realizadas por enfermeiros na Atenção Primária à Saúde, em Caxias-MA.

Materiais e Métodos: Trata-se de um estudo avaliativo, com abordagem qualitativa, que analisou as facilidades e entraves de 32 enfermeiros em relação ao gerenciamento das ações, utilizando-se o método de análise temática, proposto por Bardin.

Resultados: Averiguou-se 06 categorias temáticas. Os profissionais entenderam o gerenciamento como um dispositivo essencial relacionado às práticas de organização e supervisão do trabalho. Consideraram de grande relevância a realização do planejamento na UBS, embora uma menor parcela de profissionais afirmaram desenvolvê-lo apenas diante de uma problemática. As competências gerenciais necessárias ao enfermeiro indicaram a liderança, o poder de comunicação e atualização, bem como o conhecimento proporcionado pelas especializações As facilidades elencadas foram a participação da equipe, a autonomia dentro da UBS e o apoio fornecido pela Coordenação da Atenção Primária e Vigilância Epidemiológica do município. Verificou-se que as dificuldades existentes englobaram o relacionamento com a equipe, a escassez de recursos materiais e a falta de tempo ocasionado pela sobrecarga de atividades. Sobre as atividades gerenciais realizadas na Unidade Básica de Saúde, destacaram-se a realização das escalas dos técnicos e vigilantes, frequência dos profissionais, controle e pedido de materiais, medicamentos e vacinas, além do planejamento assistencial.

Conclusão: Observou-se que as ações gerenciais estão de acordo com as propostas pelo Ministério da Saúde, contudo há necessidade em, organizar as atividades desempenhadas e compartilhar decisões e responsabilidades a fim de que este profissional não fique sobrecarregado.

Palavras-chave: enfermagem; gestão em saúde; atenção primária à saúde; programa saúde da família.

ABSTRACT I Objective: To evaluate the management of actions carried out by nurses in primary health care in Caxias-MA.

Materials and Methods: This is an evaluative study, with qualitative approach, which analyzed the eases and barriers found by 32 nurses in relation to the management actions, using the thematic analysis method proposed by Bardin.

Results: It was established 06 thematic categories. The professionals understand management as an essential device related to organizational practices and supervision of the work. They considered of great importance to carry out the planning of Basic Health Unit (UBS), although a smaller portion of professionals implement it in a problematic scenario. Administrative competences needed by nurses indicated leadership, power of communication and updating, as well as the knowledge provided by the specializations. The eases listed were the team's participation, autonomy within the UBS and the support provided by city's Epidemiological and Primary Attention coordination. It was found that the difficulties encompassed the relationship with the team, the scarcity of material resources and lack of time caused by the overload of activities. About management activities in USB, the highlights were schedule scales of technicians and vigilants, assiduity of professionals, control and request of materials, drugs and vaccines, as well as the healthcare planning.

Conclusion: It was observed that the management actions are in accordance with the proposals by the Health Ministry, nevertheless there is a need to arrange the activities performed, share decisions and responsibilities to avoid overload work.

Keywords: nursing; health manage; primary health care; family health program. 


\section{INTRODUÇÃO}

A Atenção Primária à Saúde (APS) constitui-se no primeiro nível de atenção à saúde e atualmente é a principal estratégia de promoção da saúde em âmbito individual e coletivo. É também responsável por atuar na proteção da saúde, prevenção e diagnóstico de doenças, reabilitação e manutenção do estado de saúde, baseado nos princípios de universalidade, equidade e integralidade do cuidado ${ }^{1}$. Ademais, esta também é considerada a porta de entrada do sistema de saúde e quando funciona adequadamente, é responsável pela resolubilidade de grande parte dos problemas de saúde da população, evitando o desgaste e superlotação nos níveis secundários e terciários de assistência e vinculando os usuários aos mais diversos serviços de atenção.

A Estratégia Saúde da Família (ESF) foi criada em 1994, como forma de organizar os serviços da APS, através da reorientação do modelo assistencial, com o enfoque na atuação de equipes multiprofissionais, utilizando diferentes abordagens para os distintos contextos da realidade existente em cada localidade ou área de adscrição². A atuação das Equipes de Saúde da Família (ESF), constituídas por um grupo de profissionais pertencentes a diversas categorias, não se limita ao espaço físico da Unidade, mas devem prestar assistência nos domicílios, nas escolas, creches, centros comunitários, associações de moradores e demais locais na comunidade, buscando, através do maior contato entre o profissional, indivíduo e família, o conhecimento da realidade existente e o desenvolvimento integral de ações em saúde 3 .

De acordo com o Ministério da Saúde ${ }^{1}$, o trabalho atribuído ao enfermeiro, como membro da equipe, abrange a assistência integral aos indivíduos e famílias; o gerenciamento de recursos humanos e físicos, assim como o planejamento e avaliação das atividades desenvolvidas pelos demais profissionais da equipe de enfermagem e agentes comunitários de saúde.

A assistência de enfermagem no nível primário de atenção está inserida em um âmbito complexo, visto que o profissional produz bens e serviços à indivíduos e comunidades, devendo articular desta forma, ciência e profissionalismo. Desta forma, em consonância com Lopes Neto et al. ${ }^{4}$, o desenvolvimento da atividade gerencial surge como conduta produtiva e modificadora dos serviços e instituições, proporcionando conhecimento ao profissional e organização do trabalho a ser desempenhado. A este respeito, Kurcgant ${ }^{5}$ enfoca as dimensões existentes no trabalho gerencial de enfermagem, essa atividade envolve o planejamento de ações, o processo decisório, à capacidade de lidar com conflitos, o dimensionamento de pessoal, a responsabilidade pela educação continuada, além do controle de recursos materiais, custos e avaliação da assistência prestada.

Em consonância com Passos e Ciosak ${ }^{6}$, o gerenciamento é um indispensável instrumento do processo de trabalho, introduzido à rede básica dos serviços de saúde, demonstrando-se de fundamental importância na efetivação de políticas públicas e determinante nos processos de organização do cuidado.

Compreender a dinâmica de desenvolvimento das práticas de gerenciamento do enfermeiro na Atenção Primária à Saúde parece ser crucial para proporcionar maior qualidade da assistência e alcançar novas práticas de saúde. Dessa forma, este estudo teve como objetivo avaliar as ações gerenciais realizadas por enfermeiros atuantes na Atenção Primária à Saúde, no município de Caxias Maranhão.

\section{MATERIAIS E MÉTODOS}

Trata-se de uma pesquisa descritiva e exploratória, com abordagem qualitativa, que possibilitou uma adequada relação ao objeto deste estudo, uma vez que não se constitui em um conjunto de métodos fechados, mas compreende uma abordagem flexível, abrindo espaço para que se possa ter uma compreensão e visibilidade das atividades de gerenciamento realizadas pelo enfermeiro e, por conseguinte, perceber as facilidades e/ou dificuldades encontradas no gerenciamento das Unidades Básicas de Saúde.

O cenário desta investigação foi o Município de CaxiasMA, com uma população estimada em 161.1377. Segundo dados da Coordenação da Atenção Primária e do Sistema de Informação da Atenção Básica (SIAB) ${ }^{8}$, o município conta com 58 Equipes de Saúde da Família, distribuídas em 21 Unidades Básicas de Saúde da zona urbana e 11 da zona rural.

Dentre os profissionais de nível superior, atuantes na APS, o município conta com 58 enfermeiros, sendo 41 na Zona Urbana e 17 na Zona Rural. Assim, quanto à Zona Urbana, foram convidados para participar da pesquisa um (01) enfermeiro de cada Unidade Básica de Saúde, totalizando 21 sujeitos e o mesmo ocorreu em relação à Zona Rural, em que foram convidados 11 profissionais enfermeiros, que atuam na Saúde da Família.

De posse da lista nominal dos enfermeiros atuantes na APS, estabeleceu-se um sorteio nas unidades com duas ou mais equipes cadastradas. Assim, foram sujeitos desta pesquisa 32 enfermeiros do total de 58 atuantes na Atenção Primária à Saúde, sendo 21 sujeitos pertencentes a zona urbana e 11 que atuam na zona rural.

A coleta de dados foi norteada por um roteiro de entrevista semiestruturada aplicado pelos próprios pes- 
quisadores, nas Unidades Básicas de Saúde, em seus horários de funcionamento, em um consultório fechado para garantir a privacidade dos participantes, com duração média de 30 minutos, em horários previamente agendados com os participantes. As falas obtidas foram gravadas em aparelho MP4, e em seguida transcritas, proporcionando veracidade e fidelidade das informações. Para a análise dos dados qualitativos foram realizadas a Análise Temática de Conteúdo, proposto por Bardin ${ }^{9}$, que busca os núcleos de sentido que constituem a comunicação e cuja expressão revela algo de importante para o objeto estudado.

As entrevistas foram lidas e transcritas integralmente, procurando-se desta forma, descobrir os núcleos de sentido presentes nos depoimentos. Em uma segunda etapa, realizou-se a construção dos resultados, categorizando e realizando uma síntese das falas obtidas e buscando conceitos e referências que norteassem a análise do material. As falas dos enfermeiros da Saúde da Família, participantes da pesquisa, foram dispostas na apresentação dos resultados com a identificação da sigla referente à sua categoria profissional, seguindo uma numeração de 1 a 32, pela ordem em que os sujeitos foram entrevistados. Desta forma, estão representados como Enf.1-Enf.32.

Foram observados os aspectos éticos que regem pesquisas com seres humanos, conforme Resolução 466/12, do Conselho Nacional de Saúde. O projeto foi aprovado pelo Comitê de Ética em Pesquisa do Centro Universitário do Maranhão (UniCEUMA), com o Certificado de Apresentação para Apreciação Ética (CAAE) no 00921112.8.0000.5084.

\section{RESULTADOS E DISCUSSÃO}

Participaram do estudo 32 enfermeiros, dos quais a maioria são do sexo feminino $(87,3 \%)$, com idades que variam de 24 a 30 anos (47\%). Quanto ao estado civil, a maioria são solteiros $(56,2 \%)$, com tempo de atuação na Estratégia Saúde da Família entre 5 a 6 anos, com duas ou mais especializações, sendo que 6 enfermeiros possuem especialização em Gerenciamento de Serviços de Saúde e 25 com pós-graduação em Saúde da Família.

Os discursos produzidos durante as entrevistas permitiram a construção de seis categorias temáticas: Compreensão dos enfermeiros acerca do Gerenciamento; Conhecimento dos enfermeiros sobre planejamento; Competências Gerenciais informadas pelos enfermeiros como essenciais ao trabalho na APS; Facilidades apontadas pelos enfermeiros para o gerenciamento da UBS; Entraves apontados pelos enfermeiros para o gerenciamento da UBS e Atividades Gerenciais desenvolvidas na UBS.

\section{Compreensão dos enfermeiros acerca do Gerenciamento}

Os participantes do estudo demonstram, a partir dos discursos produzidos durante as entrevistas, uma visão de que os profissionais consideram o gerenciamento como um dispositivo adequado para conduzir a prática de enfermagem dentro da UBS, visto que possibilita o desenvolvimento de ações específicas e apropriadas que favorecem a atuação nestes serviços, conforme expressam as falas abaixo.

\begin{abstract}
"São conjuntos de ações que norteiam a prática da enfermagem, na organização das tarefas, na delegação de funções e na supervisão do trabalho a ser desenvolvido." (Enf.7)
\end{abstract}

"Gerenciamento ele pode ser entendido como uma forma de organizar, planejar e executar determinada atividade. O intuito do gerenciamento, nada mais é do que facilitar o processo de trabalho de uma determinada equipe, ou de uma determinada unidade." (Enf.19)

"Gerenciamento pra mim dentro da Atenção básica é você supervisionar as ações é... dos funcionários né?!, dos profissionais que estão sob sua supervisão, das ações que são planejadas através do planejamento. Planejar essas ações, pensar em equipe conjunto pra ta visando a melhoria da qualidade do atendimento, vendo se as ações estão sendo executadas, se as metas estão sendo executadas." (Enf.22)

Sobre o gerenciamento, Santos ${ }^{10}$, considera este como aplicável em qualquer área de atuação e, portanto dentro dos serviços de saúde o gerenciamento em enfermagem é um método racional e científico, capaz de nortear os processos de trabalho, e as ações de planejamento, execução e avaliação.

Segundo Spagnol ${ }^{11}$, o enfermeiro é o profissional capacitado para assumir a atividade gerencial, coordenar o trabalho da equipe de enfermagem, conduzir e viabilizar o processo de cuidado, devendo ter como princípio norteador de suas ações, o direito da população à assistência integral realizada de maneira efetiva e gratificante.

Nos estudos realizados por Passos e Ciosak ${ }^{6}$, é importante destacar a visão de enfermeiros do AP, ao descreveram que as ações de um gerente devem ser direcionadas ao atendimento das necessidades sociais e de saúde da população, de modo que estas possam ser trabalhadas através de uma assistência satisfatória.

É importante destacar que alguns dos profissionais definem gerenciamento como a capacidade de controlar e gerir os recursos na unidade. Os relatos abaixo evidenciam, portanto, a gerência, como a administração dos insumos 
existentes na UBS e enfatizam as atividades que como o controle de medicamentos e vacinas, planejamento quanto a aquisição e estoque de materiais e organização da estrutura física:

\begin{abstract}
“Gerenciamento é você está no comando, na direção do seu setor, direcionando vários setores, entrada, saída de medicamento, e dos funcionários. É todo o atendimento da sua unidade." (Enf.5)

"O gerenciamento ele vai ter haver não só com o planejamento das atividades, mas tem haver também com os insumos né?! com o material que a gente utiliza pra curativos, medicações né?! também o gerenciamento da sala de vacina, é toda estrutura da UBS, que ela vai ser organizada né, e gerenciada pelo enfermeiro, em colaboração também com os profissionais de cada setor." (Enf.23)
\end{abstract}

"Gerenciamento é o ato de organizar; planejar, prever, prover, todo o material necessário pra se trabalhar no caso do gerenciamento da Estratégia de Saúde da Família, pra se trabalhar com a equipe de Saúde da Família." (Enf.25)

Estes resultados assemelham-se aos estudos de Passos e Ciosak ${ }^{12}$, que descrevem o gerenciamento como um recurso que permite a solução de problemas e dificuldades administrativas, mediante a organização da unidade; aplicação de programas, controle de fluxo e assistência e utilização de recursos de forma sistematizada.

\section{Conhecimento dos enfermeiros sobre Planejamento}

As respostas obtidas nesta categoria definem $\mathrm{o}$ planejamento como um método que direciona e estrutura as ações a serem desenvolvidas na Saúde da Família. Este ainda é descrito como fundamental para o trabalho do enfermeiro, pois permite a este profissional idealizar as melhores condições para o alcance de resultados favoráveis, proporcionando ainda uma organização dos serviços assistenciais, tal como expressa as falas citadas:

“O planejamento é o processo, pelo qual determinamos que caminho devemos traçar, para chegamos a situação desejada." (Enf.11)

"Planejamento é algo que é indispensável nesse setor, como em todo setor, mas principalmente nesse: a Unidade Básica de Saúde, pois o planejamento ele é a base de tudo pra você lançar mão das estratégias pra você tá realizando a assistência." (Enf.15)

Planejar é ato indispensável no gerenciamento de programas e serviços de saúde e constataram em estudos com enfermeiros atuantes na $\mathrm{AP}$, que estes consideram o planejamento, como um importante trabalho, pois permite estabelecer objetivos e metas com vista a alcançar intervenções eficazes ${ }^{12}$.

Observa-se nos relatos, que os profissionais expressam seu entendimento sobre o planejamento através de exemplos de sua aplicação na SF. Estes enfatizam etapas de grande significância para o processo avaliativo.

O Planejamento Estratégico Situacional (PES) surge, a partir do momento em que se reconhece a diversidade de atores inserida em uma realidade complexa e dinâmica. Este possibilita a identificação das possíveis causas do problema, e a construção de planos para eliminá-las, proporciona também uma visão realista dos problemas locais sem que haja a generalização nas suas descrições e nas propostas de solução dos mesmos ${ }^{13}$.

\section{Competências Gerenciais informadas pelos enfermeiros como essenciais ao trabalho na APS}

Esta categoria versa sobre as competências gerenciais identificadas pelos enfermeiros como fundamentais para o bom trabalho na SF. Em seus discursos descrevem-se competências voltadas, para a capacidade de trabalhar com a equipe, organização, liderança, além de conhecimento técnico e científico sobre a área de atuação. Os depoimentos que seguem, reproduzem os principais achados nesta discussão.

O fato de ser um líder exige de o profissional ser detentor de inúmeras competências, visto que se percebe a liderança e o gerenciamento como vinculados nos serviços. Portanto, ao ser colocado a liderança como uma competência gerencial, deve-se destacar que está diretamente referência o poder de comunicação, o conhecimento, a organização, além de capacidade em estar à frente dos interesses do grupo para a obtenção de melhores resultados, como expostos nos relatos abaixo:

\footnotetext{
"Boa comunicação, com a equipe, a capacidade de resolver os conflitos, a liderança da equipe; saber ouvir; fazer supervisão de atividades; planejar, programar, prover." (Enf.7)
}

"Tem que ter uma boa conversa. E além de ter o conhecimento técnico dos procedimentos, de ter o conhecimento da área em que ele atua. Tem que ter uma boa interação tanto com a equipe com quem trabalha e com a comunidade." (Enf.2)

"Poder de liderança. Ser comunicativo, e ter tempo, disponível." (Enf.10)

"Ele tem que ter liderança, ele tem que ter organização, ele tem que ter compromisso, ele tem que ser empático." (Enf.25) 
Simões e Fávero ${ }^{14}$ definem liderança, como a influência de um indivíduo sobre um grupo, podendo está também ser compartilhada entre outros membros. Para os autores a liderança envolve a construção de relações interpessoais, e neste sentido a comunicação é indispensável, pois através dela o enfermeiro pode transferir e receber conhecimentos, organizar o serviço e traçar objetivos a serem atingidos juntamente com sua equipe.

Sobre estas considerações Lourenço e Trevizan ${ }^{15}$, discorrem que profissionais atuantes em diversas áreas da enfermagem, entendem a liderança como uma capacidade de influenciar um grupo através de ideias, comportamentos, atitudes e visão ampla sobre as propostas da instituição. Para estes enfermeiros, o líder deve apresentar características pessoais que facilitem a sua atuação como, flexibilidade, capacidade de ouvir e de apoiar a equipe.

Os resultados expressos nesta categoria assemelham-se aos de André e Ciampone ${ }^{16}$, que descrevem como competências essenciais na atuação da SF: o poder de comunicação com a equipe e usuários; flexibilidade; capacidade para lidar com problemas; responsabilidade; paciência e conhecimento na área de administração de saúde.

Ainda, é conveniente destacar o relato de profissionais que ao serem questionados sobre as competências necessárias para o desenvolvimento das atividades de gerência na UBS, destacam a atualização e preparo nos cursos de especialização lato senso:

“Ele tem que ter especialização né?! Dentro da área. Porque se ele vai ser gestor ele tem saber conhecer aquela realidade da comunidade. Então tem que saber o local, conhecer, ele tem que ser competente na questão de administração né?! Ele tem que ter alguma especialização, algum curso que permita ele tá gerenciando a Unidade Básica." (Enf.4)

Para estes enfermeiros as especializações são capazes de fornecer maior preparo e conhecimento nas inerentes áreas de atuação, e que desta forma apresentam-se como importantes recursos para o alcance de saberes e capacitação. Há ênfase para cursos voltados para a área da SF e também de gerência e administração, destacando-os como necessários na execução de um eficiente trabalho na UBS.

\section{Facilidades apontadas pelos enfermeiros para o gerenciamento da UBS}

Nesta categoria, observa-se que as principais facilidades apontadas no processo gerencial foram o bom relacionamento e o trabalho em equipe, a parceria com a Coordenação da APS, além da autonomia que o profissional, além própria capacidade para liderar. Os relatos a seguir descrevem:
"É o apoio da equipe como um todo, a participação da equipe durante as reuniões, saber que ta todo mundo engajado. Realmente é o apoio da equipe multidisciplinar." (Enf.22)

"A equipe é boa, tem uma boa interação entre médico, dentista os ACS's, os técnicos de enfermagem, e isso facilita bastante. A comunidade também é boa." (Enf.2)

"A facilidade é a conversa. Ta conversando sempre, aí a gente já facilita pra organizar." (Enf.17)

De Lima Trindade et al. ${ }^{17}$, salientam a importância da comunicação, e da valorização da equipe, apontandoos como fatores essenciais para o estabelecimento de relações mais flexíveis. Para os autores há a necessidade de profissionais que apostem na capacidade de colaboração dos demais membros, e preocupem-se desta forma em investir nos relacionamentos interpessoais.

Os resultados obtidos nesta categoria, são também descritos por Fernandes et al. ${ }^{18}$, que afirmam o empenho e a colaboração dos membros da equipe, como facilidades determinantes no gerenciamento. Sob essa perspectiva, verifica-se a importância do trabalho em equipe na organização dos serviços, no planejamento das ações e na construção de metas e objetivos.

O relato de profissionais que consideram a autonomia a principal facilidade em gerenciar:

"Eu me sinto autônomo dentro da minha unidade de saúde, assim eu posso palpitar, eu posso concordar, eu posso discordar, entendeu não tem aquela coisa assim autoritária, pronto e acabou, entendeu?!" (Enf.3)

Para Peduzzi e Ciampone ${ }^{19}$, a autonomia, representa aspecto de suma importância para o profissional que atua nos serviços de saúde. Estes ainda enfatizam que possuir autonomia não significa desenvolver aleatoriamente as atividades, apenas pela simples autoridade de fazê-las, mas sim possuir capacidade de desenvolvê-las através de conhecimento, pensamento crítico e avaliação.

É válido destacar a autonomia dos enfermeiros no atual cenário da saúde pública como ponto favorável ao desenvolvimento das ações gerenciais. A autonomia é capaz de proporcionar maior destaque desses profissionais enquanto líderes e administradores, contudo ressalta-se a importância em inserir os demais profissionais na construção de planos e ideias, e até mesmo nos processos que envolvem a tomada de decisão e planejamento, permitindo desta maneira a abertura e a construção de um trabalho em equipe.

As parcerias com os demais serviços públicos de saúde do município, também são de fundamental importância na consolidação da integralidade na assistência garantida pela 
resolução do SUS. Estas parcerias foram evidenciadas pelos enfermeiros, como uma facilidade no desenvolvimento das ações gerenciais na UBS. Os relatos a seguir expressam essas ideias:

"É que a gente tem um apoio muito grande por parte da coordenação por parte do secretário de saúde, da secretaria, e do município em si." (Enf.13)

Para Colomée, não há a formação de vínculos e parcerias, na busca pela solução dos problemas de saúde, as dificuldades se tornarão maiores. Isto porque muitas vezes as Unidades não detêm de informações e estratégias diante de determinada situação e por isso necessitam de apoio e direcionamento de serviços que também atuam no âmbito de saúde individual e coletiva.

Apoiando-se nas considerações descritas nesta categoria, enfatiza-se que ações articuladas entre os demais serviços da $\mathrm{AP}$, são importantes fatores para o desenvolvimento das ações na UBS, e que o gerenciamento local de saúde deve ser desenvolvido por profissionais que reconheçam a importância de liderar e reunir esforços na busca parcerias e recursos aumentando a abrangência e o grau de resolução da assistência proposta.

\section{Entraves apontados pelos enfermeiros para o gerenciamento da UBS}

As declarações evidenciam que os maiores obstáculos do gerenciamento para estes enfermeiros, estão relacionados com os recursos humanos da unidade. As ideias emitidas revelam que as dificuldades estão em atuar com indivíduos de personalidades diferentes, em ambientes marcados pela falta de comunicação, companheirismo e trabalho em equipe. Os depoimentos abaixo expressam essas dificuldades:

Ééé..existem profissionais, alguns profissionais, um pouco difíceis é de trabalhar, que não aceitam muito as condições. Mais é isso a questão pessoal." (Enf.2)

"A parte mais de recursos humanos, é a maior dificuldade." (Enf.6)

"É as dificuldades, é a falta de participação de alguns integrantes da equipe, ou então o mau trabalho realizado, a falsificação de dados, a fragmentação da equipe, esses são os principais entraves." (Enf.7)

"Ás vezes a gente tem dificuldades com relação a pessoas. Ás vezes as pessoas elas não entendem, as vezes algumas pessoas são meio não cumprem, né?! não cumprem com horário, não cumprem com seus afazeres, como deveria ser feito. É a questão dos recursos humanos dentro da unidade." (Enf.20)
Ressalta-se, que relações conflituosas na equipe, podem comprometer qualidade da assistência prestada, contribuindo para a fragmentação no atendimento e, portanto necessita de intervenções que favoreçam a comunicação e a interação entre seus componentes, promovendo ações interdependentes que condicionem competência e compromisso. É importante destacar que as relações entre a equipe de saúde foram mencionadas ao mesmo tempo como facilidade e dificuldade em gerenciar por alguns enfermeiros do estudo.

Ademais, Colomé ${ }^{20}$, destaca que as divergências entre os membros de um grupo, resultam em menor interação e participação dos mesmos no desempenho das atividades e consequentemente, em declínio na qualidade das ações. Esses problemas muitas vezes ocorrem pela convivência de vários indivíduos com personalidades distintas, que acaba por si só criando conflitos e desgaste das relações.

Neste sentido, os conflitos e as difíceis relações no ambiente de trabalho podem contribuir para a desmotivação dos componentes da equipe, que passam a atuar sem dedicação e empenho. É, portanto, imprescindível que o enfermeiro saiba lidar com os diferentes problemas que venham a existir na equipe, buscando estabelecer relações de interdependência, expondo os problemas existentes e buscando soluções favoráveis, de maneira que os limites profissionais sejam respeitados.

Os trabalhos de Simões e Fávero ${ }^{14}$ evidenciaram que os fatores que mais interferem no processo de comunicação entre a equipe de enfermagem, estão relacionados à falta de atenção e paciência; a incapacidade dos profissionais em ouvir as pessoas; e a inexistência de relacionamentos confiáveis e seguros. Estes ainda destacam que utilização estratégias como: fornecimento de uma escuta ativa, atenção e empatia, conversas e reuniões, constituem-se como práticas determinantes no relacionamento de equipes bem sucedidas.

Sobre a importância em se trabalhar com os demais profissionais, Peduzzi e Ciampone ${ }^{19}$, afirmam que não apenas as categorias existentes dentro da enfermagem, mas também as demais áreas da saúde surgiram da divisão do trabalho, e por isso devem ainda manter ligações entre si, e que apesar de suas especificidades são complementares e não devem ser vistas com total independência.

A proposta de uma equipe multidisciplinar dentro da ESF é a de justa mente, atrelar o conhecimento e ações dos profissionais, afim de que estes atuem no enfrentamento de problemas e busque uma otimização dos resultados. Diante dos resultados, ressalta-se como de suma importância o resgate pela comunicação, pois este pode diminuir as distâncias e as diferenças existentes dentro do ambiente de 
trabalho e determinante para a integralidade e o êxito das ações desenvolvidas em uma equipe.

Evidencia-se no estudo, que não apenas os problemas envoltos pelos recursos humanos são entraves para os enfermeiros, mas também a falta de recursos materiais e insumos na Unidade. Os relatos abaixo descrevem sobre o tema:

"As dificuldades geralmente a gente encontra, porque a gente planeja, a gente prever, mas na verdade a gente não tem todo o recurso necessário pra isso. Ás vezes prever um número $X$ de medicamentos, e na hora vem $X$ dividido por dois. A gente planeja ás vezes algumas estratégias, num tem recurso, então fica um pouco complicado." (Enf.25)

A escassez de recursos é descrita como dificuldade, pois segundo os depoimentos além de dificultar o planejamento das atividades, também desestimula funcionários e comunidade, limitando o enfermeiro em suas ações e atendimentos, visto que estes são problemas vão além de suas atribuições.

É importante ressaltar que o enfermeiro não participa do processo de compra dos materiais da Unidade. Contudo, é responsável pelo pedido, de medicamentos, impressos e equipamentos de acordo com a necessidade; recebimento dos mesmos quando chegam a Unidade; conferência quanto aos prazos validade, quantidades e condições; e planejamento quanto ao uso racional destes.

Segundo Castilho e Gonçalves ${ }^{21}$, a administração de recursos materiais no SUS, sempre foi motivo de preocupação em todos os níveis de assistência, isto porque os repasses dessas verbas são emitidos por licitações, que muitas atravessam processos demorados para a liberação, enquanto as instituições de saúde aguardam a provisão e a reposição insumos.

Santos, Soares e Campos ${ }^{22}$ estudaram a relação existente entre as condições de trabalho e a saúde de enfermeiros atuantes na SF e observaram que estes profissionais sofrem pela além de sofrerem pela impossibilidade de solucionarem problemas que exigem mais da estrutura e dos recursos do que realmente das suas potencialidades e competências.

Ademais, o estudo abrange o relato de enfermeiros que consideram como principais entraves: o grande número de funções desenvolvidas pelo enfermeiro na UBS.

“(...) as outras atribuições para o enfermeiro, já compromete a maior parte do tempo. É o tempo." (Enf.10)

Segundo os depoimentos existem dificuldades para os profissionais conciliarem as atividades gerenciais e de assistência, devido à grande quantidade de papéis e as inúmeras funções a cargo enfermeiro. Ademais os depoimentos relatam que a função gerencial compromete muito tempo e acabam por afastar o profissional da atuação direta no cuidado.

Contudo ressalta-se que conhecimentos abordados em momentos anteriores neste estudo, permitem enfatizar que o gerenciamento objetiva organizar a implementação do cuidado, atribuindo-lhe qualidade e satisfação, desta forma pode-se destacar a reorganização de atividades que envolvam compartilhamento e a divisão tarefas como atitude a ser repensada tentativa de aliviar a sobrecarga e a falta de tempo.

Para Jonas, Rodrigues e Resck ${ }^{23}$, a enfermagem muitas vezes distancia-se das atividades assistenciais, por estar envolvido nas atividades administrativas como o controle de materiais; preenchimento de impressos, supervisão da equipe, comunicação com a coordenadoria de saúde e demais atividades exigidas no trabalho da UBS.

Observa-se também que muitos ambientes de saúde, há uma inversão deste fato, de forma que os enfermeiros mais atuantes no processo assistencial podem distanciar-se das atividades de gerência. Desta forma $\mathrm{Greco}^{24}$ expõe a necessidade em articular as ações de enfermagem, de modo a organizar e distribuir as ações prioritárias na construção de um cuidado integral, mesmo com as limitações existentes.

\section{Atividades Gerenciais desenvolvidas na UBS}

Os relatos expressam inúmeras funções desenvolvidas como: a construção de escalas, o controle de frequências, provisão de materiais e vacinas a elaboração de boletins ambulatoriais, o planejamento de atividades, supervisão de profissionais e avaliação quanto às metas e déficits em algum programa.

"Escala de visitas domiciliares; Pedidos de medicamentos; atualização e atividades em sala de vacina; produção mensal; levantamento de dados em gerais; freqüência e atividade dos Agentes comunitários de Saúde. Controle de utilização e duração de materiais; Limpeza e palestras." (Enf.8)

"Estamos sempre verificando na sala de curativos também, os materiais que estão vencidos, o quê que ta faltando, os recursos que estão faltando pra poder fazer os pedidos. Nos casos dos programas de saúde também, faz aquela previsão das medicações que iremos utilizar durante o mês, e aí todo mês a gente vai ta fazendo a solicitação desses medicamentos. Além disso, temos que ficar verificando a sala de imunização, a assistência que os técnicos fazem a clientela. E assim ficar tá o tempo todo verificando o que precisa ser melhorado. E como equipe multiprofissional a gente verifica, o que o que está faltando também no consultório dentário, 
pra conversar com o dentista sempre, pra tá fazendo sempre algumas melhoras, pra ta fazendo solicitação de medicações essas coisas." (Enf.14)

"A escala que é realizado dos profissionais vigilantes, a escala das auxiliares de enfermagem. É toda a parte de imunobiológicos, insumos e os medicamentos. $O$ boletim ambulatorial, que é a produção, e desde o planejamento, com a implementação de atividades fora como o desenvolvimento de atividades no programa saúde na escola É necessário também que sempre que a gente veja, que a gente ta em baixa com alguma meta." (Enf.15)

É interessante destacar a preocupação existente com as necessidades dos demais profissionais da equipe, e aos demais setores da unidade, desta forma: o enfermeiro é responsável também pela supervisão e organização dos trabalhos dos profissionais vigilantes, realizando também as escalas de frequências e faltas, destes profissionais. Quanto à limpeza da unidade, verifica-se que esta também é regulada pelo enfermeiro, assim como o estoque de materiais, utilizado.

$\mathrm{Greco}^{24}$ destaca as atividades de provisão e previsão de recursos e insumos para a unidade, a supervisão e orientação da equipe, a delegação de funções; a avaliação dos serviços desempenhados de cuidado e assistência como atividades de gerência necessárias ao adequado funcionamento da UBS

Os resultados encontrados nesta categoria assemelhamse aos descritos por Brondani Júnior et al. ${ }^{25}$, onde as ações gerenciais descritas pelos enfermeiros dentro da ESF, englobavam, o preenchimento de relatórios, o estabelecimento de reuniões com a equipe, a educação continuada, o planejamento de atividades, e controle dos recursos materiais.

Os relatos a seguir fazem referência ao gerenciamento do cuidado, e versam sobre a organização da assistência dispensada aos usuários:

"A questão do planejamento, o planejamento tanto na questão de, educação em saúde, é...Planejamento assistencial, planejamento pra gente ta indo atrás desses pacientes." (Enf.6)

"Conciliar as funções assistências com as funções administrativa... É, verificar a qualidade do atendimento, as queixas, trazidas não só pela equipe, mas como também pelos usuários no dia-a-dia. Planejar o trabalho da equipe." (Enf.26)

Estes ainda enfatizam que o enfermeiro não deve priorizar somente os problemas da equipe, mas que este também seja conhecedor das dificuldades dos usuários. O enfoque a essa questão, além de evidenciar o interesse do profissional em garantir assistência, cria aberturas para a população expor as dificuldades e insatisfações sobre os serviços dispensados.
Em consonância com Felli e Peduzzi ${ }^{26}$, o trabalho dos enfermeiros sempre esteve envolto de duas dimensões: uma assistencial e outra de gerenciamento. A parte assistencial abrange a formação de intervenções às necessidades apresentadas por um grupo ou indivíduo e tem por finalidade o cuidado integral, em contrapartida na gerência o enfermeiro prima pela organização do trabalho e recursos humanos em enfermagem, com a finalidade de condicionar o desempenho de ações adequadas de cuidado.

\section{CONSIDERAÇÕES FINAIS}

De acordo com o objetivo proposto, é importante ressaltar que os enfermeiros do estudo apresentam relativa experiência na rede de Atenção Primária à Saúde, com especializações na área e tempo de atuação significativo frente às ações e encargos neste nível de assistência.

O estudo aponta, ainda, que os profissionais entendem o gerenciamento como um dispositivo determinante no processo de trabalho do enfermeiro. Apresentaram ainda definições teóricas abrangentes associando este às questões de planejamento, organização de serviços, distribuição e supervisão de atividades, direção e controle sobre os recursos físicos, humanos e materiais. Ademais a gerência é entendida como um instrumento capaz de garantir e proporcionar a qualidade da assistência no nível primário de atenção à saúde.

Quanto às facilidades no desenvolvimento das atividades gerenciais, foram evidenciadas: o bom relacionamento com a equipe; a autonomia que o profissional possui na UBS; a capacidade de liderança e o apoio fornecido pela Coordenação da Atenção Primária, que ao fornecerem informações relevantes sobre metas, programas e campanhas, proporcionam uma articulação entre os serviços da APS no município.

Sobre os entraves no gerenciamento da Unidade, destacaram-se: os recursos; a escassez de recursos materiais, e a falta de tempo ocasionado pela sobrecarga de atividades. Ao apontarem os recursos humanos como uma dificuldade, a maioria dos enfermeiros atribui este fato, à falta de comunicação e participação de membros da equipe, o que acaba gerando conflitos e desgastes que afetam diretamente as relações interpessoais e podem comprometer a qualidade da assistência.

Destaca-se, no estudo a magnitude envolta do processo gerencial, e o desenvolvimento deste na UBS pelo enfermeiro que apresenta-se, através de uma visão voltada não apenas para a atuação da equipe de enfermagem, mas ampliada para os demais profissionais. Por fim destaca-se a necessidade em repensar sobre as práticas de gerenciamento, visando 
aproximá-las da assistência e da prestação de cuidado, articulando-as sob a perspectiva de mudanças positivas nos serviços de saúde.

\section{REFERÊNCIAS}

1. Brasil. Ministério da Saúde. Secretaria de Atenção à Saúde. Departamento de Atenção Básica. Política nacional de atenção básica. Brasília: Ministério da Saúde; 2006. 114 p.

2. Saito RXS. Políticas de Saúde: princípios, diretrizes e estratégias para a estruturação de um sistema único de Saúde. In: Ohara ECC, Saito RXS. Saúde da Família: considerações teóricas e aplicabilidade. São Paulo: Martinari; 2010. 424 p.

3. Brasil. Ministério da Saúde. Secretaria de Atenção à Saúde. Departamento de Atenção Básica. Vigilância em Saúde: Dengue, Esquistossomose, Hanseníase, Malária, Tracoma e Tuberculose. 2ª ed. rev. Brasília: Ministério da Saúde; 2008. 119 p.

4. Lopes Neto D, Guidão JMC, Silva MS. Gerenciamento do processo de mudança em enfermagem. In: Harada MJCS, organizador. Gestão em enfermagem. São Paulo: Yendis; 2011. 256 p.

5. Kurcgant P, coordenador. Gerenciamento em enfermagem. Rio de Janeiro: Guanabara Koogan; 2005.

6. Passos JP, Ciosak SI. A concepção dos enfermeiros no processo gerencial em Unidade Básica de Saúde. Rev Esc Enferm USP. 2006;40(4):464-8. http://dx.doi.org/10.1590/S0080-62342006 000400003

7. Instituto Brasileiro de Geografia e Estatística. Cidades [Internet]; 2015 [citado em 2016]. Disponível em: http://www.ibge.gov.br/ cidadesat.

8. PMC/SMS. Secretaria Municipal de Saúde. Coordenação da Atenção Primária à Saúde. Sistema de Informação da Atenção Básica. Caxias: SMS/Prefeitura de Caxias; 2013.

9. Bardin L. Análise de conteúdo. São Paulo: Edições 70; 1997. 225 p.

10. Santos SR. Administração aplicada à enfermagem. 3a ed. João Pessoa: Ideia; 2007. 237 p.

11. Spagnol CA. Repensando a gerência em enfermagem a partir de conceitos utilizados no campo da saúde coletiva. Ciênc Saúde Coletiva. 2005;10(1):119-27. http://dx.doi.org/10.1590/S141381232005000100019

12. Passos JP, Ciosak SI. Planejamento e gerência: as duas faces de uma mesma moeda. R. Pesq.: Cuid. Fundam. 2004;8(1/2):25-32.

13. Melleiro MM, Tronchin DMR, Ciampone MHT. O planejamento estratégico situacional no ensino do gerenciamento em enfermagem. Acta Paul Enferm. 2005;18(2):165-71 http://dx.doi.org/10.1590/ S0103-21002005000200008
14. Simões ALA, Fávero N. O desafio da liderança para o enfermeiro. Rev Latino-am Enfermagem. 2003;11(5):567-73. http://dx.doi. org/10.1590/S0104-11692003000500002

15. Lourenço MR, Trevizan MA. Líderes da enfermagem brasileira - sua visão sobre a temática da liderança e sua percepção a respeito da relação liderança \& enfermagem. Rev Latino-am Enfermagem. 2001;9(3):14-9. http://dx.doi.org/10.1590/S010411692001000300003

16. André AM, Ciampone MHT. Competências para a gestão de Unidades Básicas de Saúde: percepção do gestor. Rev Esc Enferm USP. 2007;41:835-40. http://dx.doi.org/10.1590/s008062342007000500017

17. De Lima Trindade L, Coelho Amestoy S, Adyles Muniz L, L. Biolchi T, Pires de Pires DE, Schubert Backes VM. Influência dos estilos de liderança do enfermeiro nas relações interpessoais da equipe de enfermagem. Enfermería Glob. 2011;10(22):1-9.

18. Fernandes MC, Barros AS, Silva LMS, Nóbrega MFB, Silva MRF, Torres RAM. Análise da atuação do enfermeiro na gerência de unidades básicas de saúde. Rev Bras Enferm. 2010;63(1):11-5. http://dx.doi.org/10.1590/S0034-71672010000100002

19. Peduzzi M, Ciampone MHT. Trabalho em equipe e processo grupal. In: Kurcgant P, coordenador. Gerenciamento em Enfermagem. Rio de Janeiro: Guanabara Koogan; 2005.

20. Colomé ICS. Trabalho em equipe no Programa de Saúde da Família na concepção de enfermeiras [dissertação]. Porto Alegre: UFRGS; 2005. 97 p.

21. Castilho V, Gonçalves VLM. Gerenciamento de recursos materiais. In: Kurcgant $\mathrm{P}$, coordenador. Gerenciamento em enfermagem. Rio de Janeiro: Guanabara Koogan; 2005. p. 157-70.

22. Santos VC, Soares CB, Campos CMS. A relação trabalho-saúde de enfermeiros do PSF no município de São Paulo. Rev Esc. Enferm USP. 2007;41(Esp):777-8.

23. Jonas LT, Rodrigues HC, Resck ZM. A função gerencial do enfermeiro na Estratégia Saúde da Família: limites e possibilidades. Rev APS. 2011;14(1):28-38.

24. Greco RM. Relato de Experiência: Ensinando a administração em enfermagem através da educação em saúde. Rev Bras Enferm. 2004;54(4):504-7. http://dx.doi.org/10.1590/S003471672004000400026

25. Brondani Júnior DA, Heck RM, Ceolin T, Viegas CRS. Atividades gerenciais do enfermeiro na estratégia de saúde da família. Rev Enferm UFSM. 2011;1(1): 41-50.

26. Felli VEA, Peduzzi M. O trabalho gerencial em enfermagem. In: Kurcgant $\mathrm{P}$, coordenador. Gerenciamento em enfermagem. Rio de Janeiro: Guanabara Koogan; 2005. p. 1-13. 